\title{
Stress among university students: the psychometric properties of the Italian version of the SBI-U 9 scale for Academic Burnout in university students
}

\author{
Silvia Platania, Santo Di Nuovo, Alice Caruso, Fabio Digrandi, Pasquale Caponnetto \\ Department of Educational Sciences, University of Catania, Catania, Italy
}

\begin{abstract}
Several authors have highlighted the importance of creating a useful tool to evaluate academic Burnout through the construction and validation of specific scales to evaluate academic Burnout. Based on the literature, the aim of this study is to evaluate in Italian university the psychometric properties of the SBI-U 9 scale for Academic Burnout in university students in Italy developed by Boada-Grau and colleagues. Study $1(\mathrm{~N}=609)$ examined the factor structure of the scale $\left(\right.$ Male $=45.6 \%$, Female $=54.4 \% ; \mathrm{M}_{\text {age }}=21.9$; $\mathrm{SD}=2.92)$. Study $2(\mathrm{~N}=412)$ advanced the previous $\mathrm{SBI}-\mathrm{U} 9$ validation by testing its measurement equivalence across gender $($ Male $=48.8 \%$, Female $=51.2 \%)$ and different type of course of study (Technical-Mathematical-Scientific $=33.5 \%$, MedicalScientific $=32.5 \%, \quad$ Scientific-Humanistic $=34 \%$ ) through Multigroup Confirmatory Factor Analysis. Results confirmed a one higher-order factor structure with three first-order factors, the scale was found to be invariant across gender and different type of course of study. The findings advanced the general claim of SBI-U 9 showed an important tool for detecting the academic Burnout in university students in the Italian context, this is confirmed by the good psychometric properties of the scale.
\end{abstract}

Correspondence: Silvia Platania, Department of Educational Sciences, University of Catania, Palazzo Ingrassia Via Biblioteca, 4, 95124, Catania, Italy

Tel: +393402630932

E-mail: splatani@unict.it

Key words: Burnout, invariance, psychometrics, students, stress.

Contributions: the authors contributed equally.

Conflict of interest: The authors declare no conflict of interest.

Funding: None.

Conflict of interests: the authors report no conflict of interests.

Received for publication: 25 June 2020.

Revision received: 18 July 2020.

Accepted for publication: 20 July 2020.

This work is licensed under a Creative Commons AttributionNonCommercial 4.0 International License (CC BY-NC 4.0).

(C) Copyright: the Author(s), 2020

Licensee PAGEPress, Italy

Health Psychology Research 2020; 8:9209

doi:10.4081/hpr.2020.9209

\section{Introduction}

Burnout syndrome is considered a psychosocial syndrome. It was identified, for the first time in the early 1970s in human service workers and especially in health care workers (Maslach, Schaufeli, \& Leiter, 2001).

Later on, Maslach \& Jackson (1981) described Burnout as a pathological state of a stressor process related to occupations characterized by intense interpersonal relationships resulting from chronic workplace stress that has not been successfully managed (Pines \& Maslach., 1978).

They developed the Maslach Burnout Inventory (MBI) to detect and measure the burnout syndrome entity. The scale assesses three variables: emotional exhaustion, reduced depersonalization of personal achievement at work (Maslach \& Leiter, 2001).

Burnout syndrome is considered a psychological state resulting from prolonged exposure to job stressor and it has been described as an inability to cope with emotional stress at work (Pines \& Maslach, 1978) as excessive use of energy and resources leading to feelings of failure and exhaustion (Freudenberger,1986).

Burnout is also described in the 11th Revision of the International Classification of Diseases (ICD-11) as an "occupational phenomenon" that is characterized by three dimensions us feelings of exhaustion, feelings of cynicism related to one's job and reduced professional efficacy. Also, the World Health Organization defined Burnout as an "official occupational phenomenon". Burnout syndrome refers specifically to phenomena in the occupational context and should not be applied to describe experiences in other areas of life. (World Health Organization, 2019).

Christina Maslach, defined Burnout as "a psychological syndrome that emerges as a prolonged response to chronic interpersonal stressors at work". She defined three distinct types of Burnout: individual Burnout caused by personality factors (e.g. perfectionism); Interpersonal Burnout caused by difficult relationships with colleagues; Organizational Burnout caused by an inadequate organization, (e.g. extreme requests and unrealistic deadlines etc. (Schaufeli, Maslach \& Marek, 1993).

Burnout syndrome has been studied in many areas of work. The most important of these are socio-health workers such as nurses, physiotherapists, university professors, teachers, council workers, traffic police, prison officers, etc. (Boada-Grau, Merino-Tejedor, Sánchez-García, Prizmic-Kuzmica, \& Vigil-Colet, 2015).

Research studies on academic Burnout focused on students attending health courses. Among these are medical students (DeAbreu, Grosseman, De Oliva, \& De Andrade, 2011; Backović, Živojinović, Maksimović, \& Maksimović, 2012; Costa, Santos, Rodrigues, \& Vieira, 2012; Kains \& Piquard, 2011; Prinz, Hertrich, Hirschfelder, \& de Zwaan, 2012; Santen, 2010; Young, Fang, Golshan, Moutier, \& Zisook, 2012), nursing students (Botti, Foddis, 
\& Giacalone-Olive 2011), dental students (Campos, Jordani, Zucoloto, Bonafé, \& Maroco, 2012), pharmacy students (Ried, Motycka, Mobley, \& Meldrum, 2006) and physiotherapy students (González, Souto, Fernandez, \& Freire, 2011).

This syndrome of emotional exhaustion, depersonalization, and reduced personal accomplishment may be applied to all individuals who engage in activities that are psychologically similar to work, such as students (Magnano, Santisi, \& Platania, 2017; Maslach et al., 2016). The MBI questionnaire has been adapted not only for the professions of human services but for all professions in general.

Many research studies have applied the MBI-General Survey (MBI-GS) scale (Maslach \& Jackson, 1981) to students, although it was originally created to assess Burnout in the general population.

Later Schaufeli, Martinez, Pinto, Salanova, \& Bakker, (2002) created a student-specific burn-out scale, called the MBI-Student Survey (MBI-SS). Several studies have been conducted with university students (Adie \& Wakefield, 2011; Gan, Shang, \& Zhang, 2007; Martínez \& Marques Pinto, 2005; Martínez, Marques Pinto, \& Lopes da Silva, 2000-2001; Palacio, Caballero, González, Gravini, \& Contreras, 2012; Rostami, Reza, \& Schaufeli, 2012; Salanova, Martínez, Bresó, Llorens, \& Grau, 2005; FigueiredoFerraz, Gil-Monte, \& Grau-Alberola, 2013; Schaufeli, et al. 2002).

To solve the problems associated with the MBI, the Spanish Burnout Inventory (SBI) was created. Several authors have highlighted the importance of creating a useful tool to evaluate academic Burnout through the construction and validation of specific scales to evaluate academic Burnout. (Caballero, Hederich, \& Palacio, 2010; Salmela-Aro, Kiuru, Leskinen, \& Nurmi, 2009). In this regard, a more recent line of research is conducted by Salmela-Aro et al. (2009), who created and validated the schoolBurnout inventory scale (SBI-9). This tool has been used in several countries with higher education students, both university and nonuniversity. It was used in Finland (Salmela-Aro \& Kunttu, 2010), with Spanish student students, in Peru (Merino, Delgadillo, \& Caballero 2013) and in Colombia (Aguilar -Bustamante \& RiañoHernandez, 2013).

The School Burnout Inventory (SBI) is therefore a specific tool for assessing Burnout syndrome in adolescent students. The translation, adaptation of the SBI and its psychometric properties were tested in a Spanish sample.

The results demonstrate that the adapted version of the SBI is a valid way to measure burnout in Spanish teenagers. However, the creation of new subscales seems necessary for an adequate application of the Burnout measure in an academic context (Moyano \& Riaño-Hernández, 2013)

The literature is full of studies evaluating the relationship of academic burnout with different individual, situational or contextual variables. Individual variables include flexibility, temperament, selfesteem, and gender. Situational or contextual variables that have been studied in relation to Burnout among students include school climate, social support, the major academic, academic performance and coursework (Soliemanifar \& Shaabani, 2013; Platania, Gruttadauria, Citelli, Giambrone, \& Di Nuovo, 2017).

In recent years, researchers have classified self-efficacy as one of the individual factors effective in explaining the phenomenon of Burnout (Schaufeli et al. 1993; Schaufeli et al. 2002). Self-efficacy is defined as the belief that a person can do something successfully (Woolfolk, 2004). Some of the previous research studies have confirmed the relationship between self-efficacy and burnout (Yang \& Farn, 2005; Hobfoll \& Freedy, 1993).

Researches indicate that variables like self-efficacy self-esteem, locus of control, emotional stability, extraversion, conscientiousness, positive affectivity, negative affectivity, optimism, proactive personality (Bateman \& Crant, 1993; Santisi, Platania, \& Hichy, 2014; Platania, Morando, \& Santisi, 2017) and hardworking impact highly on burnout (Maslach et al.,2001; Maslach \& Jackson, 1984).

\section{The aim of study}

Based on the literature, the aim of this study is to evaluate the psychometric properties of the SBI-U 9 scale for Academic Burnout in university students in Italy developed by Boada-Grau and colleagues (2015). In the original study, the questionnaire has shown very good psychometric properties in terms of factorial structure, external, discriminant and convergent validity. The SBI-U consists of 9 items assessed on 3 subscales (Exhaustion, Cynicism and Inadequacy). Specifically, for the Italian context, very few studies have used the construct of Burnout among university students. Specifically, our study is particularly aimed at: i) to verify if there is any psychometric difference to the whole scale when applied to a different culture; ii) deepen the Spanish validation study by exploring its measurement equivalence across gender and Areas of study (Cheung, 2008; Vandenberg, \& Lance, 2000) because this statistical procedure was not included in the Spanish validation of the scale (Byrne, 2008); iii) Assessing the discriminant validity and criterion validity of the scale. Two studies were carried out to achieve these aims: in the first study, we hypothesized that the SBI$\mathrm{U}$ scale would show the same factor structure found in the Boada-Grau and colleagues' study (Hypothesis 1). In the second study, we replicated the best fitting solution we hypothesized (Hypothesis 2) that the Italian version of the SBI-U will show measurement equivalence (Cheung, 2008) across gender (men vs. women) and Areas of study (Technical-Mathematical-Scientific, Medical-Scientific, Scientific-Humanistic) ${ }^{1}$; Finally, we hypothesized that the SBI-U will show positive and significant correlations with some criterion-related variables (Hypothesis 3).

\section{Method}

\section{Participants and procedure}

The sample of study 1 consisted of 609 university students enrolled in a first-level degree course. The data was gathered by three Italian universities (Catania $=41.9 \%$, Padua $=29.7 \%$, Rome $=28.4 \%$ ), $45.6 \%$ of the sample were men and $54.4 \%$ women $\left(\mathrm{M}_{\text {age }}=21.9 ; \mathrm{SD}=2.92\right), 6.4 \%$ were working students and $7.9 \%$ were out of regular course students. The participation was voluntary. Questionnaires were administered individually and anonymously. Participants were recruited through a link published in several social media groups. The first part of the questionnaire consisted of an informed consent form, where respondents were informed of the voluntary and anonymous nature of their participation, the aim of the research and the fact that they were free to voluntary abandon the study at any moment without any penalty.

${ }^{1}$ Technical-Mathematical-Scientific area includes courses of study in Mathematics, Physics, Chemistry and Engineering; Medical-Scientific courses of study in Medicine, Healthcare Professions, Biology; Scientific-Humanistic= course of study in Psychology, Pedagogy, Philosophy, Political Science, Economic Science and Law. 


\section{Measures}

\section{School Burnout Inventory-University (SBI-U)}

The School Burnout Inventory-University (SBI-U; Boada-Grau et al., 2015) was drawn up for the purpose of evaluating Burnout among the university students. this scale is a Spanish adaptation of Salmela and colleagues' SBI-9 (2009), developed to measure Burnout among adolescents in secondary education (16 years old). The scale consists of 9 items assessed on a Likert type scale (from $1=$ Completely disagree to $6=$ Completely agree) and 3 subscales (Exhaustion, Cynicism and Inadequacy). In the original validation study, the Reliability of the three factors was: Exhaustion (0.80), Cynicism (0.80) and Inadequacy (0.67) respectively. The ratios in the Spanish version were acceptable ranging between 0.70 and 0.77. Following the recommendations made by Beaton, Bombardier, Guillemin and Ferraz (2000), a back-translation procedure has been applied during the adaptation, with the process including the following steps: translation and adaptation of the original scale from Spanish to Italian, back translation and review committee. A bilingual Italian-Spanish interpreter translated the Spanish version of the SBI-U scale into Italian.

\section{Mesure du Stress Psychologique (M.S.P.)}

MSP (Lemyre \& Tessier, 1990; Italian translation and adaptation: Di Nuovo, Rispoli \& Genta, 2000), is a questionnaire consisting of 49 items aimed at measuring the perceived state of tension, with reference to the cognitive aspects - affective, physiological and behavioral stress. The items are collected in six clusters: Cluster I - Loss of irritability control; Cluster II Psychophysiological sensations; Cluster III - Sense of effort and confusion; Cluster IV - Depressive anxiety; Cluster V - Pain and physical problems; Cluster VI - Hyperactivity, acceleration, behavior. The answers for each item are provided on a scale from 1 to 4 , where 1 indicates "not at all" and 4 "very much". The overall final score is obtained by adding the values of each item, rendered unidirectional, in which the agreement indicates a low level of stress. The validity of the Italian study of the overall score of the M.S.P. is $\alpha=0.95$.

\section{Data Analysis}

Linear structural equations models were calibrated to test the hypothesized model. Tests were completed in AMOS 26.0 (Arbuckle, 2014) applying the maximum likelihood method.

A sequence of CFA analyses was carried out on the dataset, to establish the best factor model to fit the data.

The models' goodness of fit was evaluated using the Tucker Lewis Index (TLI), the Comparative Fit Index (CFI), the Root Mean Square Error of Approximation (RMSEA) and the Standardized Root Mean Square Residual (SRMR). Furthermore, $\chi^{2}$ values and $\Delta \chi^{2}$ values between the competing models are presented, but they are sensitive to sample size (Meade, Johnson \& Braddy, 2008), so Akaike Information Criterion (AIC) was also presented and
Bayesian Information Criterion (BIC) (lower values indicate better fit). $\triangle$ CFI was also used with values not exceeding 0.01 indicating that the models are equivalent in terms of fit (Cheung \& Rensvold, 2002). Other well-known analytical tools such as correlations were also used, which were implemented by using SPSS 26.0.

\section{Results}

\section{Confirmatory factor analysis}

At first, a model with three-factor made of three first-order factors with co-variances among them (Model 1) was tested, and the following fit indexes were obtained: $\chi 2(23)=141.806$, SRMR $=0.031$, RMSEA $=0.072, \mathrm{CFI}=0.97, \mathrm{TLI}=0.95, \mathrm{AIC}=185.806$, $\mathrm{BIC}=282.866$. Model 1 was then compared to a one second-order factor model and three first-order factors (Model 2), $[\chi 2(24)=204.723, \quad \mathrm{SRMR}=.043, \quad \mathrm{RMSEA}=0.08, \quad \mathrm{CFI}=0.95$, $\mathrm{TLI}=0.92, \mathrm{AIC}=246.723, \mathrm{BIC}=339.371]$. The first model of the two showed the best fit to the data, based on fit indexes, AIC, BIC and delta Chi-square value $\left(\Delta \chi^{2} \mathrm{M} 2-\mathrm{M} 1(1)=62.917\right)$. Given the close relationship between two of them Model 1 was then compared to a two-factor model might be more suitable than the three-factor structure (Model 3), $\quad[\chi 2(26)=206.089, \quad \mathrm{SRMR}=0.052$, $\mathrm{RMSEA}=0.11, \mathrm{CFI}=0.92, \mathrm{TLI}=0.88, \mathrm{AIC}=284.089, \mathrm{BIC}=366.904]$ and it showed again the best fit to the data $\left(\Delta \chi^{2} \mathrm{M} 3-\mathrm{M} 1(3)=\right.$ 64.283). Moreover, all factor loadings were significant at $\mathrm{p}<0.001$ and varied between 0.59 and 0.83 , with a mean of 0.75 . Fit indexes for the tested models are presented in Table 1 .

\section{Concurrent Validity}

We next examined correlations between three factors of SBI-U (Exhaustion, Cynicism and Inadequacy) and six factors of MSP (Loss of irritability control, Psychophysiological Sensations, Sense of Effort and Confusion, Depressive anxiety, Pain and Physical Problems, Hyperactivity, Acceleration, Behavior). Descriptive statistic and correlation matrix for the study variables shown in Table 2. Cronbach's Alpha was computed for each factor to test reliability and showed good internal consistency of the scale: CR 0.93, AVE 0.68 for Exhaustion, CR 0.90, AVE 0.61 for Cynicism, CR 0.92, AVE 0.62 for Inadequacy, for Loss of irritability Control CR 0.93, AVE 0.75, for Psychophysiological Sensations CR 0.94, AVE 0.75, for Sense of Effort and Confusion CR 0.96, AVE 0.78, for Depressive Anxiety CR 0.90, AVE 0.61, Pain and Physical Problems CR 0.91, AVE 0.64. and for Hyperactivity, Acceleration, Behavior CR 0.89, AVE 0.63.

The high positive relationship $(r=0.75, \mathrm{p}<0.001)$ between Loss of irritability Control, Pain and Physical Problems $(r=0.72, p<0.001)$ and Exhaustion, confirms the congruency between these constructs. Moreover, Cynicism has high correlation with Pain and Physical Problems $(\mathrm{r}=0.48, \mathrm{p}<0.001)$ and Psychophysiological Sensations $(\mathrm{r}=0.43, \mathrm{p}<0.001)$.

Table 1. Fit indexes for models tested in CFA (Study 1).

\begin{tabular}{|c|c|c|c|c|c|c|c|c|c|}
\hline & $\chi^{2}$ & df & SRMR & RMSEA & RMSEA 90\%-C.I. & CFI & TH & AIC & BIC \\
\hline Model 1a & $141.806^{*}$ & 23 & 0.03 & 0.072 & $0.059-0.087$ & 0.97 & 0.95 & 185.806 & 282.866 \\
\hline Model $2^{\mathrm{b}}$ & $204.723^{*}$ & 24 & 0.04 & 0.08 & $0.071-0.098$ & 0.95 & 0.92 & 246.723 & 339.371 \\
\hline Model 3c & 206.089 & 26 & 0.05 & 0.11 & $0.090-0.121$ & 0.92 & 0.88 & 284.089 & 366.904 \\
\hline
\end{tabular}

${ }^{\text {a }}$ Model 1: three first-order factors with co-variances among them; ${ }^{\mathrm{b}}$ Model 2: one second-order factor and three first-order factors; ${ }^{\mathrm{c}}$ Model 3 : two-factor model with co-variances among them. ${ }^{*} \mathrm{p}<0.001$. 
Another important positive correlation is between Inadequacy and Loss of irritability Control $(\mathrm{r}=0.53, \mathrm{p}<0.001)$, this confirms the relationship between Feelings of inadequacy and associated with overt moods of hostility and aggression. all correlations confirm the high degree of congruence between the constructs expressed by the scales taken into consideration. This supported our Hypothesis 1 .

\section{Method}

\section{Participants and procedure}

Study 2 involved 412 participants (48.8\% were men), aged between 18 to 27 years $\left(M_{\text {age }}=21.5, S D=2.8\right) ; 33.5 \%$ were enrolled in Technical-Mathematical-Scientific type of course of study, $32.5 \%$ were enrolled in Medical-Scientific type of course of study and 34\% in Scientific-Humanistic type course of study. $5.6 \%$ were working students and $8.5 \%$ were out of course students. Participants were recruited through a link published in several social media groups.

\section{Measure}

\section{Self-Esteem Scale}

The Rosenberg Self-Esteem Scale (1965), a widely used selfreport instrument for evaluating individual self-esteem. A 10-item scale that measures global self-worth by measuring both positive and negative feelings about the self. The scale is believed to be unidimensional. All items are answered using a 4-point Likert scale format ranging from strongly agree to strongly disagree.

\section{General Self-Efficacy scale}

The General Self-Efficacy Scale is a 10-item (Schwarzer \& Jerusalem, 1995). Generalized Self-Efficacy that is designed to assess optimistic self-beliefs to cope with a variety of difficult demands in life. The scale has been originally developed in German by Matthias Jerusalem and Ralf Schwarzer in 1981. In opposition to other scales that were designed to assess optimism, this one explicitly refers to personal agency. Perceived self-efficacy is a prospective and operative construct. The scale is available in 33 languages at http://userpage.fu-berlin.de/ health/selfscal.htm. In samples from 23 nations, Cronbach's alphas ranged from 0.76 to 0.90 , with the majority in the high $0.80 \mathrm{~s}$. All items are answered using a 4-point Likert scale format ranging from Not at all true to Exactly true.

\section{School Burnout Inventory-University (SBI-U)}

Burnout in university students was measured with the SBI-U (Boada-Grau et al., 2015)), using 9 items assessed on a Likert type scale (from $1=$ Completely disagree to $6=$ Completely agree) and 3 subscales (Exhaustion, Cynicism and Inadequacy).

\section{Data Analysis}

Linear structural equation models (Bagozzi, 1994) were calibrated to test the hypothesized model. Tests were completed in AMOS 26.0 applying the maximum likelihood (ML) method. At first, we conducted a confirmatory factor analysis (CFA) to confirm the factor structure of the SBI-U in an independent sample. Next, a series of multiple group CFA were run, in which different, and progressively more stringent forms of measurement equivalence were tested (Cheung 2008 Vandenberg \& Lance 2000). By establishing whether factor loadings, intercepts and residual variances are equivalent in a factor model that measures a latent concept, we can assure that comparisons that are made on the latent variable are valid across groups or time (Van de Schoot Lugtig \& Hox, 2012, p.3). Other well-known analytical tools such as correlations were also used, which were implemented by using SPSS 26.0.

\section{Results}

\section{CFA}

Results of the CFA for the SBI-U 9 indicated the following estimates of model fit: $\chi^{2}(2)=83.443$ SRMR $=0.04$, RMSEA $=0.08$, $\mathrm{CFI}=0.97, \mathrm{TLI}=0.96, \mathrm{AIC}=131.443, \mathrm{BIC}=227.947$. Moreover, all factor Loadings are significant at $\mathrm{p}<0.001$ and varied between 0.57 and 0.78 , with a mean of 0.69 .

\section{MCFA for Gender}

At the first step multiple-group analysis tested a model of configural invariance (Model 1) by simultaneously evaluating the fit of male and female samples. The fit indices $\left(\chi^{2}(42)=114.376\right.$, $\mathrm{p}<0.001 ; \mathrm{TLI}=0.94 ; \mathrm{CFI}=0.96 ; \mathrm{SRMR}=0.034 ; \mathrm{RMSEA}=0.065$ ) indicated a good fit for this model, supporting an equivalent solution made of one second-order factor with three first-order factors for SBI-U 9 in the data sets for both men and women (Table 3).

Criteria for metric invariance were also met (Table 3). More importantly, $\Delta \chi^{2}{ }_{\mathrm{M} 2-\mathrm{M} 1}(4)=5.25$ and $\Delta \mathrm{CFI}=0.001$ suggested that

Table 2. Descriptive statistics, reliability, composite reliability, average variance extracted and inter-correlations for study $1(\mathrm{~N}=457)$.

\begin{tabular}{|c|c|c|c|c|c|c|c|c|c|c|c|c|c|}
\hline & M & SD & $\alpha$ & AVE & CR & 1 & 2 & 3 & 4 & 5 & 6 & 7 & 8 \\
\hline Exhaustion & 3.46 & 0.99 & 0.85 & 0.68 & 0.93 & - & & & & & & & \\
\hline Cynicism & 3.56 & 0.83 & 0.71 & 0.61 & 0.90 & $0.55^{* *}$ & - & & & & & & \\
\hline Inadequacy & 3.75 & 0.86 & 0.85 & 0.62 & 0.92 & $0.58 * *$ & $0.43 * *$ & - & & & & & \\
\hline LoC & 3.46 & 1.22 & 0.87 & 0.75 & 0.93 & $0.75^{* *}$ & $0.31^{* *}$ & $0.53^{* *}$ & - & & & & \\
\hline PS & 4.25 & 0.91 & 0.88 & 0.75 & 0.94 & $0.52^{* *}$ & $0.43^{* *}$ & $0.52^{* *}$ & $0.33 * *$ & - & & & \\
\hline SoEaC & 2.11 & 1.23 & 0.91 & 0.78 & 0.96 & $0.50^{* *}$ & $0.30 * *$ & $0.26^{* *}$ & $0.50^{* *}$ & 0.09 & - & & \\
\hline $\mathrm{DA}$ & 1.86 & 0.86 & 0.72 & 0.61 & 0.90 & $0.48 * *$ & $0.30 * *$ & $0.26 * *$ & $0.48 * *$ & 0.04 & $0.66 * *$ & - & \\
\hline $\mathrm{PaPP}$ & 2.93 & 0.96 & 0.86 & 0.64 & 0.91 & $0.72 * *$ & $0.48 * *$ & $0.35^{* *}$ & $0.58^{* *}$ & $0.39 * *$ & $0.60 * *$ & $0.55^{* *}$ & - \\
\hline $\mathrm{HAB}$ & 2.13 & 0.81 & 0.76 & 0.63 & 0.89 & $0.26^{* *}$ & 0.06 & 0.07 & $37^{* *}$ & $21^{* *}$ & $31^{* *}$ & $29 * *$ & $33^{* *}$ \\
\hline
\end{tabular}

Note. LoC= Loss of irritability Control; PS= Psychophysiological Sensations; SoEaC= Sense of Effort and Confusion; DA= Depressive Anxiety; PaPP= Pain and Physical Problems; HAB= Hyperactivity, Acceleration, Behavior; p scores: ${ }^{*}<0.05,{ }^{* *}<0.01,{ }^{* * *}<0.001$. 
Model 2 could be considered equivalent to Model 1. Thus, metric invariance was supported.

Also, measurement scalar invariance (as tested by Model 3) and error invariance (Model 4) were found $\left(\Delta \chi 2_{\mathrm{M} 3-\mathrm{M} 2}(10)=6.83\right.$, $\Delta \mathrm{CFI}=0.001 ; \Delta \chi 2_{\mathrm{M} 4-\mathrm{M} 3}(5)=13.31, \Delta \mathrm{CFI}=0.001$.

The equivalence in factor variances was tested (Model 5) and it was found to be tenable $\left(\Delta \chi 2_{\mathrm{M} 5-\mathrm{M} 4}(3)=5.95, \Delta \mathrm{CFI}=0.000\right)$. Finally, the equivalence in factor covariances was tested (Model 6) by nesting the respective model with Model 9, and the result was that it was supported $\left(\Delta \chi 2_{\mathrm{M} 6-\mathrm{M} 5}(6)=10.41, \Delta \mathrm{CFI}=0.000\right)$. Results were totally satisfactory as the model fit proved to be invariant across both populations and they supported our Hypothesis 2 (Table 3).

\section{MCFA for different type of course}

In addition, we have further conducted a multi-group analysis was tested on a configurational invariance model (Model 1), by simultaneously evaluating the fit of university of different type of course in different areas of study (Technical-MathematicalScientific; Medical-Scientific; Scientific-Humanistic). The fit indices $\quad\left[\left(\chi^{2}(63)=131.129, \quad \mathrm{p}<0.001 ; \quad \mathrm{TLI}=0.94 ; \quad \mathrm{CFI}=0.97\right.\right.$; $\mathrm{SRMR}=0.057$; RMSEA=0.051)] indicated a good fit for this model, supporting an equivalent solution made of one second-order factor with three first-order factors for SBI-U 9 in the data sets for all three of different areas of study: Technical-Mathematical-Scientific, Medical-Scientific and Scientific-Humanistic (Table 4). Model 2 was tested for metric equivalence. Results indicated that Model 2 could be considered equivalent to Model 1, as $\Delta \chi^{2}{ }_{\mathrm{M} 2-\mathrm{M} 1}(10)=28.51$ and $\Delta \mathrm{CFI}=0.000$. Thus, metric invariance was supported. Model 3 tested for scalar invariance $\chi^{2}\left(\Delta \chi^{2}{ }_{\mathrm{M} 3-\mathrm{M} 2}(11)=26.68\right)$ the $\Delta \mathrm{CFI}=0.001$ suggested that scalar equivalence was supported.

Also, measurement error invariance (as tested by Model 4) was found $\left(\Delta 2_{\mathrm{M} 4-\mathrm{M} 3}(5)=10.11, \Delta \mathrm{CFI}=0.001\right.$.

We then proceeded by testing equivalence in factor variances and it was found to be supported (Model 5, $\Delta \chi_{\mathrm{M} 5-\mathrm{M} 4}(7)=18.56$, $\triangle \mathrm{CFI}=0.000)$. Finally, we tested the equivalence in factor covariances (Model 6, $\left.\Delta \chi 2_{\mathrm{M} 6-\mathrm{M} 5}(6)=8.88, \Delta \mathrm{CFI}=0.000\right)$ and was found. Therefore, our results provided support for Hypothesis 2 . Results can be seen in Table 4 .

\section{Criterion validity}

Table 5 showed descriptive statistics, Cronbach's $\alpha$ and bivariate correlations for the variables of Study 2. As expected, the SBI-U 9 scale showed significant and negative correlations with all the variables, according to literature. Specifically, it showed the highest correlations between Exhaustion and Self-Efficacy $(\mathrm{r}=-0.23 * *$, $\mathrm{p}<0.001)$, and Self-Esteem $\left(\mathrm{r}=-0.27^{* *}, \mathrm{p}<0.001\right)$, followed by negative correlation between Cynicism with Self-efficacy $(\mathrm{r}=-$ $\left.0.24^{* *}, \mathrm{p}<0.001\right)$ and Cynicism and self-esteem $(\mathrm{r}=-0.21 * *$, $\mathrm{p}<0.001$ ). Finally, the third factor of the SBI-U 9 Scale, Inadequacy, also correlates negatively with self-efficacy $\left(\mathrm{r}=-0.20^{* *}, \mathrm{p}<0.001\right)$.

Table 3. Fit statistics for measurement invariance by gender.

\begin{tabular}{lccccc}
\hline Model & $\chi^{2}(\mathrm{df})$ & CFI & SRMR & & RMSEA \\
1. Configural Invariance & $114.376(42)$ & 0.96 & 0.03 & $0.07(0.051-0.079)$ & - \\
2. Metric Invariance & $119.625(46)$ & 0.95 & 0.04 & $0.06(0.048-0.063)$ & 0.001 \\
\hline 3. Scalar Invariance & $126.456(56)$ & 0.95 & 0.04 & $0.06(0.048-0.063)$ & 0.001 \\
4. Measurement error Invariance & $139.763(61)$ & 0.95 & 0.03 & $0.06(0.048-0.063)$ & 0.001 \\
\hline 5. Structural Variance Invariance & $145.709(64)$ & 0.95 & 0.04 & $0.06(0.048-0.063)$ & 0.000 \\
6. Structural Covariance Invariance & $156.121(70)$ & 0.95 & 0.04 & $0.06(0.048-0.063)$ & 0.000 \\
\hline
\end{tabular}

Table 4. Fit statistics for measurement invariance by different type of course of study.

\begin{tabular}{|c|c|c|c|c|c|}
\hline Model & $\chi^{2}(d f)$ & CFI & SRMR & RMSEA & $\triangle \mathrm{CF}$ \\
\hline 1. Configural Invariance & $131.129(63)$ & 0.97 & 0.06 & $0.05(0.039-0.064)$ & - \\
\hline 2. Metric Invariance & $159.641(73)$ & 0.97 & 0.06 & $0.05(0.034-0.058)$ & 0.000 \\
\hline 3. Scalar Invariance & $186.320(84)$ & 0.97 & 0.06 & $0.05(0.034-0.058)$ & 0.001 \\
\hline 4. Measurement error Invariance & $196.425(89)$ & 0.97 & 0.06 & $0.05(0.034-0.058)$ & 0.001 \\
\hline 5. Structural Variance Invariance & $215.733(96)$ & 0.97 & 0.06 & $0.05(0.034-0.058)$ & 0.000 \\
\hline 6. Structural Covariance Invariance & $224.612(102)$ & 0.97 & 0.06 & $0.05(0.034-0.058)$ & 0.000 \\
\hline
\end{tabular}

Table 5. Descriptive statistics and Pearson correlations between study variables.

\begin{tabular}{llllccc} 
& M & SD & $\alpha$ & 1 & 2 & 3 \\
1. Exhaustion & 5.21 & 1.05 & 0.86 & - & & \\
2. Cynicism & 4.97 & 1.20 & 0.78 & $0.79^{* *}$ & - & - \\
\hline 3. Inadequacy & 5.56 & 1.17 & 0.88 & $0.80^{* *}$ & $0.77^{* *}$ & $-0.20^{* *}$ \\
4. Self Efficacy & 5.04 & 1.03 & 0.89 & $-0.23^{* *}$ & $-0.24^{* *}$ & - \\
\hline 5. Self Esteem & 4.45 & 1.09 & 0.91 & $-0.27^{* *}$ & $-0.21^{* *}$ & $-0.17^{* *}$ \\
\hline
\end{tabular}

Note: $p$ scores: ${ }^{*}<0.05,{ }^{* *}<0.01,{ }^{* * *}<0.001$. 
and self-esteem $\left(\mathrm{r}=-0.17^{* *}, \mathrm{p}<0.001\right)$.

The present findings are in line with literature, as psychological stress was found to be strongly related with measures of general self-efficacy (Boada-Grau et al., 2015), as well as a self-esteem Therefore, the criterion validity of the scale was confirmed (Hypothesis 3).

\section{Discussion}

The aim of this study was to examine the psychometric properties of the Burnout School Inventory in the form of University SBI-U 9 in the Italian context. To accomplish this, we used different procedures. Confirmative Factor Analyses and Multigroup Confirmative Factor Analyses using Structural Equation Modelling were performed to verify the factorial structure of the scale. Results were consistent with the original findings (Boada-Grau et al., 2015), indicated a one higher-order factor structure, composed of three first-order factors.

In particular, the first study confirmed that the Italian version of the SBI-U 9 scale confirmed the stability of the factor structure identified in the original Spanish version.

In the second study, we performed the validity of the scale through two multigroup confirmatory factor analysis to test whether the scale is invariant across gender and different type of course of study. In none of the other validation studies was the invariance measurement procedure used (Salmela-Aro et al., 2009; BoadaGrau et al., 2015). We conducted two invariance tests in order to verify the psychometric equivalence of the perception of the scale for both the gender variable and the different type of course of study variable because only when such equivalence is established, researchers can proceed with examining mean group differences (Vandenberg \& Lance, 2000).

Results from the multigroup confirmatory factor analysis showed that the same factor solution was invariant across gender (men, women) and different types of course of study TechnicalMathematical-Scientific, Medical-Scientific, Scientific-Humanistic). This implies that Italians conceptualize the SBI-U 9 in the same way (Byrne, 2008); furthermore, the present study found evidence for metric invariance, uniqueness invariance, scalar and structural invariance, which means that the relationship between the constructs was the same across the groups.

Another objective was corroborated given that the reliability evaluated by computing Cronbach's alpha, composite reliability and average variance extracted (given the multidimensionality of the scale) of the three factors was found to be appropriate of the scale, showed very good values. Furthermore, concurrent validity and criterion validity confirmed the adequacy of the scale. Through concurrent validity, we were able to determine the congruence of the scale with the same type of construct (through correlation with the MSP) amount of agreement between two different assessments; while with the criterion validity we were able to ascertain measures how well one measure predicts an outcome for another measure. A test has this type of validity if it is useful for predicting performance or behaviour in another situation. The validity of the criterion confirmed the correlation with self-efficacy and self-esteem confirming what is already present in the literature.

From the results that emerged through the psychometric procedures used we can therefore conclude that the SBI-U 9 has all the qualities useful to be used as a tool for detecting academic Burnout in the Italian context.

\section{Limitations and practical implications}

The limits of the research represent more than anything else stimuli for prospects of the study. The first limit is in line with the limit expressed by Spanish colleagues in the validation of the Spanish version of the scale. Longitudinal studies need to be carried out to further determine the relationship between academic burn would be useful out and other variables such as the year of the student's course.

Another limitation indicated by them is the fact of not considering other variables such as year of the course and number of subjects repeated. We have tried to overcome this limit by inserting the multi-group analysis by type of study course. We realize, however, that further study in this regard would be useful. We therefore propose in a future study to compare with a multiwave drawing the data obtained with students who are almost at the end of the academic path by carrying out a longitudinal comparison that would allow us to determine the adequacy of the scale in the measure of academic Burnout.

Finally, further studies involving other countries are needed to verify whether the same factor solution, with three dimensions loading to the higher-order SBI-U 9, is found to best fit the data.

Despite these limitations, however, the results lead to important suggestions for future research and interventions; the present findings show SBI-U 9 to display an excellent fit plus good discriminant, convergent, criterion and construct validities, as well as good reliability.

\section{References}

Adie, J., \& Wakefield, C. (2011). Perceptions of the teaching environment,engagement and Burnout among university students on a sportsrelated degree programme in the UK. Journal of Hospitality, Leisure, Sport \& Tourism Education, 10, 74-84.

Aguilar-Bustamante, M., \& Riaño-Hernandez, D. (2013). Propiedades psicométricas del "School Burnout Inventory" SBI en población colombiana adolescente. Psychometric properties of the "School Burnout Inventory" SBI in teenage Colombian population

Arbuckle, J.L. (2014). IBM SPSS Amos 23 user's guide. IBM, Amos Development Corporation. Retrieved from $\mathrm{ftp}: / /$ public.dhe.ibm.com/software/analytics/spss/documentation /amos/23.0/ en/Manuals/IBM_SPSS_Amos_User_Guide.pdf

Backović, D., Živojinović, J. I., Maksimović, J., \& Maksimović, M. (2012). Gender differences in academic stress and Burnout among medical students in final years of education. Psychiatria Danubina, 24, 175-181.

Bagozzi, R.P. (1994). Structural equation models in marketing research: Basic principles. In: Bagozzi, R.P., Principles of marketing research. Oxford, Blackwell.

Bateman, T.S. \& Crant, J.M. 1993. The proactive component of organizational behavior: A measure and correlates. Journal of Organizational Behavior, 14(2), 103-118.

Beaton, D. E., Bombardier, C., Guillemin, F. \& Ferraz, M. B. (2000). Guidelines for the process of cross-cultural adaptation of self-report measures. Spine, 25, 3186-3191.

Boada-Grau, J., Merino-Tejedor, E., Sánchez-García, J.C., PrizmicKuzmica, A.J., \& Vigil-Colet, A. (2015). Adaptation and psychometric properties of the SBI-U scale for Academic Burnout in university students. Anales De Psicología / Annals of Psychology, 31(1), 290-297. 
Botti, G., Foddis, D., \& Giacalone-Olive, A.M. (2011). Preventing Burnout in nursing students. Soins, 755, 21-23.

Byrne, B.M. (2008). Testing for multigroup equivalence of a measuring instrument: A walk through the process. Psicothema, 20(4), 872-882.

Caballero, C.C., Hederich, C., \& Palacio, J. E. (2010). El Burnout académico: delimitación del síndrome y factores asociados con su aparición [The academic Burnout: delineation of the syndrome and factors associated with its development]. Revista Latino americana de Psicología, 42, 131-146.

Campos, J.A., Jordani, P.C., Zucoloto, M.L., Bonafé, F.S., \& Maroco, J. (2012). Burnout syndrome among dental students. Revista Brasileira Epidemiologia, 15, 155-165.

Cheung, G.W. (2008). Testing equivalence in the structure, means, and variances of higher-order constructs with structural equation modeling. Organizational Research Methods, 11(3), 593-613.

Cheung, G.W. \& Rensvold, R.B. (2002). Rensvold Evaluating Goodness-of-Fit indexes for testing measurement invariance. Structural Equation Modeling: A Multidisciplinary Journal, 9, 233-255.

Costa, E. F., Santos, S., Rodrigues, A. T., \& Vieira, E. (2012). Burnout syndrome and associated factors among medical students: A cross-sectional study. Clinics (Sao Paulo), 67, 573580.

De-Abreu, A.T, Grosseman, S., De-Oliva, E.F., \& De-Andrade, T.M. (2011). Burnout syndrome among internship medical students. Medical Education, 45, 1146-1150.

Di Nuovo, S., Rispoli, L., \& Genta, E. (2000). Misurare lo stress. Milano: Franco Angeli.

Figueiredo-Ferraz, H., Gil-Monte, P.R., \& Grau-Alberola, E. (2013). Psychometric properties of the "Spanish Burnout Inventory" (SBI): Adaptation and validation in a Portuguese-speaking sample. European Review of Applied Psychology / Revue Européenne de Psychologie Appliquée, 63(1), 33-40.

Freudenberger, H.J. (1986). The issues of staff Burnout in therapeutic communities. Journal of Psychoactive Drugs, 18:247-251.

Gan, Y., Shang, J., \& Zhang, Y. (2007). Coping flexibility and locus of control as predictors of Burnout among chinese college students. Social Behavior and Personality, 35, 1087-1098.

González, R., Souto, A., Fernández, R., \& Freire, C. (2011). Regulación emocional y Burnout académico en estudiantes universitarios de Fisioterapia [Emotional regulation and academic Burnout in university students Physiotherapy]. Revista de Investigación en Educación, 9, 7-18.

Hobfoll, S.E., \& Freedy, J. (1993). Conservation of resource: a general stress theory applied to Burnout. In Schanfeli WB, Maslach C, Marek T. (eds.), Professional Burnout: recent developments in theory and research. Washington, DC: Taylor \& Francis;:115-129.

Jerusalem, M., \& Schwarzer, R. (1999). Allgemeine Selbstwirksamkeit. In Schwarzer, R., Jerusalem, M., (Ed.), Skalen zur Erfassung von Lehrer-und Schülermerkmalen (p. 1314). Berlin: Freie Universität Berlin.

Kains, E., \& Piquard, D. (2011). The Burnout of medical students. Revue Medicale de Bruxelles, 32, 424-430.

Lemyre, L., Tessier, R., \& Fillion, L. (1990). Mesure de stress psychologique (MPS), Manual d'utilisation Behaviora, Brossard-Quebec.

Magnano, P., Santisi, G., Platania, S. (2017). Emotional intelligence as mediator between burnout and organizational outcomes. International Journal of Work Organisation and Emotion, 8(4), 305-320.
Martínez, I. M., Marques Pinto, A., \& Lopes da Silva, A.L. (20002001). Burnout em estudantes do ensino superior [Burnout in students of higher education]. Revista Portuguesa de Psicologia, 35, 151-167.

Martínez, I. M., \& Marques Pinto, A. (2005). Burnout en estudiantes universitarios de España y Portugal y su relación con variables académicas [Burnout in university students from Spain and Portugal and its relation to academic variables]. Aletheia, 21, 21-30.

Maslach, C., Schaufeli, W.B. \& Leiter, M.P. (2001). Job Burnout. Annual Review of Psychology, 52: 397-422.

Maslach, C. \& Jackson, S.E. 1984. Burnout in organizational settings. Applied Social Psychology Annual, 5: 133-153.

Maslach, C., \& Jackson, S.E. 1981. The measurement of experienced Burnout. Journal of Occupational Behavior, 2: 99113.

Maslach, C., \& Leiter, M.P. (2016). Understanding the burnout experience: recent research and its implications for psychiatry. World Psychiatry, 15(2),103-111.

Meade, A.W., Johnson, E.C., \& Braddy, P.W. (2008). Power and sensitivity of alternative fit indices in tests of measurement invariance. The Journal of applied psychology, 93(3), 568-592. https://doi.org/10.1037/0021-9010.93.3.5688.

Moyano, N., \& Riaño-Hernández, D. (2013). Burnout escolar en adolescents españoles: Adaptación y validación del School Burnout Inventory [School Burnout in Spanish adolescents: Adaptation and validation of School Burnout Inventory] Ansiedad y Estrés, 19, 95-103.

Merino, C., Delgadillo, A., \& Caballero, R. (2013). Burnout en adolescentes: Validez e structural del inventario de Burnout escolar (SBI) [Burnout in adolescents: structuestructural del inventario de Burnout escolar (SBI). Burnout in adolescent: structural validity School Burnout Inventory (SBI). Paper presented at the 34Interamerican Congress of Psychology, 1519 July, Brasilia (Brazil).

Palacio, J. E., Caballero, C. C., González, O., Gravini, M., \& Contreras, K. P. (2012). Relación del Burnout y las estrategias de afrontamiento con el promedio académico en estudiantes universitarios [Relationship of Burnout and coping strategies with academic average in college students]. Universitas Psychologica, 11, 535-544.

Pines A, \& Maslach C. Characteristics of staff Burnout in mental health settings. Hospital \& Community Psychiatry 1978; 29:233-237.

Platania S., Gruttadauria, S., Citelli, G., Giambrone L., \& Di Nuovo, S. (2017) Associations of Thalassemia Major and satisfaction with quality of life: The mediating effect of social support, Health Psychology Open, July-December 2017: 1-9. DOI: 10.1177/2055102917742054.

Platania S., Morando M., \& Santisi G., (2017). The Phenomenon of Brand Hate: Analysis of Predictors And Outcomes, Quality Access to Success 18(S2), pp.342-347. ISSN 1582-2559.

Prinz, P., Hertrich, K., Hirschfelder, U., \& de Zwaan, M. (2012). Burnout, depression and depersonalisation-psychological factors and coping strategies in dental and medical students. GMS Zeitschrift fur medizinische Ausbildung, 29(1).

van de Schoot, R., Lugtig, P., \& Hox, J. (2012) A checklist for testing measurement invariance. European Journal of Developmental Psychology, 9(4), 486-492, DOI:10.1080/17405629.2012.686740.

Ried, L., Motycka, C., Mobley, C., \& Meldrum, M. (2006). Comparing Burnout of student pharmacists at the founding campus with student pharmacists at a distance. American 
Journal of Pharmaceutical Education, 70, 114-126.

Rosenberg, M. (1965). Society and the adolescent self-image. Princeton, NJ: Princeton University Press.

Rostami, Z., Reza, M., \& Schaufeli, W.B. (2012). Dose interest predicts academic Burnout? Interdisciplinary Journal of Contemporary Research in Business, 3, 877-885.

Salanova, M., Martínez, I.M., Bresó, E., Llorens, S., \& Grau, R. (2005). Bienestar psicológico en estudiantes universitarios: Facilitadores y obstaculizadores del desempeño académico. [Psychological well-being in college students: Facilitating and hindering academic performance] Anales de Psicología, 21, 170- 180.

Salmela-Aro, K., Kiuru, N., Leskinen, E., \& Nurmi, J. E. (2009). School-Burnout Inventory (SBI) - Reliability and validity. European Journal of Psychological Assessment, 25, 48-57.

Salmela-Aro, K., \& Kunttu, K. (2010). Study Burnout and engagement in higher education. Unterrichtswissenschaft, 38, 318-332.

Santen, S. A. (2010). Burnout in medical students: examining the prevalence and associated factors. Southern Medical Journal, 103, 758-763.

Santisi, G., Platania, S., \& Hichy, Z. (2014). A lifestyle analysis of young consumers: a study in Italian context. Young Consumers 15(1), PP.94-104, ISNN: 1747-3616.ISSN: 1121-4228. https://doi.org/10.1108/YC-03-2013-00357

Schaufeli, W.B., Maslach, C., \& Marek, T. (1993). Professional Burnout: Recent developments in theory and research. Philadelphia: Taylor \& Francis.

Schaufeli, W.B., Martinez, I.M., Pinto, A.M., Salanova, M., \&
Bakker, A.B. (2002). Burnout and engagement in university students: A cross-national study. Journal of cross-cultural psychology, 33(5):464-81.

Schwarzer, R., \& Jerusalem, M. (1995). Generalized Self-Efficacy scale. In Weinman, J., Wright, S., \& Johnston, M. Measures in health psychology: A user's portfolio. Causal and control beliefs (pp. 35-37). Windsor, UK: NFER-NELSO.

Soliemanifar, O., \& Shaabani, F. 2013. The Relationship Between of Personality Traits and Academic Burnout in Postgraduate Students. Journal of Life Science and Biomedicine, 3(1): 60-63 Vandenberg, R. J., \& Lance, C. E. (2000). A review and synthesis of the measurement invariance literature: Suggestions, practices, and recommendations for organizational research. Organizational Research Methods, 3(1), 4-70.

Woolfolk, A. (2004). Educational psychology. 9th edition. Boston, MA: Allyn and Bacon.

World Health Organization, 2019. Burn-out an "occupational phenomenon": International Classification of Diseases. Mental health.

Yang, H., Farn, C.K. (2005). An investigation of the factors MIS student Burnout in technical- vocational college. Computers in Human Behavior, 21, 917-932.

Young, C., Fang, D., Golshan, S., Moutier, C., \& Zisook, S. (2012). Burnout in premedical undergraduate students. Academic Psychiatry, 36, 11-16. 